\title{
Learning best-practices in journalology: course description and attendee insights into the inaugural EQUATOR Canada Publication School
}

Jacqueline Galica ${ }^{1 *}$, Alyssandra Chee-a-tow ${ }^{2}$, Shikha Gupta ${ }^{3}$, Atul Jaiswal ${ }^{3}$, Andrea Monsour ${ }^{2}$, Andrea C. Tricco ${ }^{4,5}$, Kelly D. Cobey ${ }^{6,7,8}$ and Nancy J. Butcher ${ }^{2}$

From EQUATOR Canada Publication School

Toronto, Canada. 05-06 October 2017

\begin{abstract}
Background and purpose: Dissemination of research results is a key component of the research continuum and is commonly achieved through publication in peer-reviewed academic journals. However, issues of poor quality reporting in the research literature are well documented. A lack of formal training in journalology (i.e., publication science) may contribute to this problem. To help address this gap in training, the Enhancing the QUAlity and Transparency Of health Research (EQUATOR) Canada Publication School was developed and facilitated by internationally-renowned faculty to train researchers and clinicians in reporting and publication best practices. This article describes the structure of the inaugural course and provides an overview of attendee evaluations and perspectives.

Key highlights: Attendees perceived the content of this two-day intensive course as highly informative. They noted that the course helped them learn skills that were relevant to academic publishing (e.g., using reporting guidelines in all phases of the research process; using scholarly metrics beyond the journal impact factor; open-access publication models; and engaging patients in the research process). The course provided an opportunity for researchers to share their challenges faced during the publication process and to learn skills for improving reproducibility, completeness, transparency, and dissemination of research results. There was some suggestion that this type of course should be offered and integrated into formal training and course curricula.

Implications: In light of the importance of academic publishing in the scientific process, there is a need to train and prepare researchers with skills in Journalology. The EQUATOR Canada Publication School provides an example of a successful program that addressed the needs of researchers across career trajectories and provided them with resources to be successful in the publication process. This approach can be used, modified, and/or adapted by curriculum developers interested in designing similar programs, and could be incorporated into academic and clinical research training programs.
\end{abstract}

Keywords: Medical education, Publication science, Scholarly communications, Reporting quality

\footnotetext{
* Correspondence: jacqueline.galica@queensu.ca

${ }^{1}$ School of Nursing, Faculty of Health Sciences, Queen's University, Kingston,

Canada

Full list of author information is available at the end of the article
}

(c) The Author(s). 2018 Open Access This article is distributed under the terms of the Creative Commons Attribution 4.0 International License (http://creativecommons.org/licenses/by/4.0/), which permits unrestricted use, distribution, and reproduction in any medium, provided you give appropriate credit to the original author(s) and the source, provide a link to the Creative Commons license, and indicate if changes were made. The Creative Commons Public Domain Dedication waiver (http://creativecommons.org/publicdomain/zero/1.0/) applies to the data made available in this article, unless otherwise stated. 


\section{Background}

Dissemination of study results is a key component of the research-to-practice continuum [1]. One traditional and common method of disseminating research findings to the scientific community is through publications in peer-reviewed academic journals. However, only half of completed research projects are eventually published [2-5], and of those that do manage to be published, many are fraught with errors and/or are poorly reported [6]. Together, these issues of publication bias and poor quality reporting contribute to a lack of transparency and prevents reproducibility and critical appraisal of study results, rendering them unusable [7]. Common reporting deficiencies include the provision of incorrect or misleading information (e.g., incorrect statistical analyses), missing or incomplete information (e.g., missing treatment or outcome details in methods), inconsistent information (e.g., between trial protocols and reports), and poorly written or inappropriately used tables, text, or figures [6]. Collectively, these problems highlight numerous avoidable challenges in the scholarly publication of research.

Currently, little is known about how to best train authors for academic publishing [8] and authors instead typically develop these skills through a process of trial and error [9] and/or from their academic supervisors [10]. Globally, national granting agencies are increasingly specifying that grantees disseminate their research results to the widest possible audience at the earliest opportunity to improve the sharing and uptake of research results (e.g., [11]). To ensure their research findings are effectively disseminated, as well as compliance to these types of granting policy mandates, it is essential that researchers are educated on journalology best practices and that they finesse skills related to writing and publication. One freely accessible online resource that is available to support researchers in this respect is the Enhancing the QUAlity and Transparency Of health Research (EQUATOR) Network [12, 13].

The EQUATOR Network is an international collaboration that promotes the transparent and accurate reporting of research and provides a searchable website that includes a library for research reporting guidelines, as well as practical help and resources (e.g., toolkits) for writing and peer-reviewing research articles. Reporting guidelines are tools that authors can use as they draft their manuscripts to ensure that all relevant information pertaining to their research is articulated in a standardized manner [12]. The EQUATOR Network's reporting guidelines facilitate the critical appraisal of published studies and increases the reproducibility, completeness, and transparency of research reports [12, 14]. To further facilitate improvements in reporting quality, journal publishers are increasingly requiring that these checklists accompany manuscripts submitted by authors [12, 14, 15]. The Network includes centres in Australasia [16], Canada [17],
France [18] and the United Kingdom [19]. It also hosts courses and workshops internationally to help researchers improve their research reporting and dissemination skills such as the five-day UK EQUATOR Center Publication School [20]. In 2017, researchers at The Hospital for Sick Children in collaboration with the EQUATOR Canada Centre organized and led the inaugural EQUATOR Canada Publication School.

The purpose of this manuscript is to: 1) to describe the inaugural EQUATOR Canada Publication School facilitated by a faculty (collectively referred to as the 'EQUATOR Canada Publication School Faculty'); and 2) to describe attendee evaluations and perspectives from participating in the EQUATOR Canada Publication School (also referred to as the 'Publication School'). The authors of this paper include Publication School attendees (JG, AC, SG, AJ, AM) and members of the Publication School Faculty and planning committee (ACT, KC, NB). The views expressed herein represent those of the authors who attended the Publication School as trainees (JG, AC, SG, AJ, AM). Publication School Faculty co-authors (ACT, $\mathrm{KC}, \mathrm{NB}$ ) contributed course content information and aggregate results of all attendee evaluations. In the following sections, we describe the Publication School curriculum and structure; present the main themes of attendee evaluation and feedback; and discuss attendee recommendations proposed at the close of the course.

\section{About the EQUATOR Canada publication school}

The inaugural EQUATOR Canada Publication School took place from October 5-6, 2017 at the Hospital for Sick Children's Peter Gilgan Centre for Research and Learning in Toronto, Ontario, Canada. The Publication School was funded by the Ontario Strategy for Patient-Oriented Research Support Unit (OSSU, [21]), which is an initiative supported by the Government of Ontario and Canadian Institutes of Health Research that fosters engagement from clinicians, patients, researchers, policy makers, and industry representatives to collaborate and implement Canada's Strategy for Patient-Oriented Research within Ontario [21]. The EQUATOR Canada Publication School was accredited as a Continuing Professional Development (CPD) course through the University of Toronto for 11-credit hours with the Royal College of Physicians and Surgeons of Canada (Section 1) and the College of Family Physicians of Canada (Mainpro+). Such accreditation is useful for attendees with professional designations that require continuing education credits to maintain their certification and encourages participation by clinician-researchers.

The Publication School was led by expert faculty in publication science and consisted of clinicians, scientists, professors, and communications specialists from major hospitals and academic institutions in Ontario (Table 1). 
Table 1 EQUATOR Canada 2017 Publication School Faculty and Planning Committee

\begin{tabular}{|c|c|}
\hline Name & $\begin{array}{l}\text { EQUATOR Canada Publication School Role } \\
\text { and Professional Affiliation(s) }\end{array}$ \\
\hline \multirow[t]{2}{*}{ Nancy Butcher, PhD } & $\begin{array}{l}\text { Co-director, Course faculty, and Planning } \\
\text { Committee member }\end{array}$ \\
\hline & $\begin{array}{l}\text { Senior Research Associate, The Hospital } \\
\text { for Sick Children }\end{array}$ \\
\hline \multirow[t]{3}{*}{ Martin Offringa, MD, PhD } & $\begin{array}{l}\text { Co-director, Course faculty, and Planning } \\
\text { Committee member }\end{array}$ \\
\hline & $\begin{array}{l}\text { Senior Scientist \& Staff Neonatologist, } \\
\text { The Hospital for Sick Children }\end{array}$ \\
\hline & Professor, University of Toronto \\
\hline \multirow[t]{4}{*}{ Kelly Cobey, PhD } & $\begin{array}{l}\text { Course faculty and Planning Committee } \\
\text { member }\end{array}$ \\
\hline & $\begin{array}{l}\text { Investigator, Centre for Journalology, } \\
\text { The Ottawa Hospital }\end{array}$ \\
\hline & Adjunct Professor, University of Ottawa \\
\hline & Staff, EQUATOR Canada Centre \\
\hline \multirow[t]{4}{*}{ David Moher, PhD } & $\begin{array}{l}\text { Course faculty and Planning Committee } \\
\text { member }\end{array}$ \\
\hline & $\begin{array}{l}\text { Senior Scientist, Centre for Journalology, } \\
\text { The Ottawa Hospital }\end{array}$ \\
\hline & $\begin{array}{l}\text { Associate Professor and University } \\
\text { Research Chair, University of Ottawa }\end{array}$ \\
\hline & Director, EQUATOR Canada Centre \\
\hline \multirow[t]{2}{*}{ Peter Gill, MD, PhD } & $\begin{array}{l}\text { Course faculty and Planning Committee } \\
\text { member }\end{array}$ \\
\hline & $\begin{array}{l}\text { Pediatric Resident, The Hospital for } \\
\text { Sick Children }\end{array}$ \\
\hline \multirow[t]{4}{*}{ Richard Glazier, MD, MPH } & $\begin{array}{l}\text { Course faculty and Planning Committee } \\
\text { member }\end{array}$ \\
\hline & Family Physician, St. Michael's Hospital \\
\hline & Scientist, Li Ka Shing Knowledge Institute \\
\hline & Professor, University of Toronto \\
\hline \multirow[t]{3}{*}{ Andrea Tricco, PhD } & $\begin{array}{l}\text { Course faculty and Planning Committee } \\
\text { member }\end{array}$ \\
\hline & Scientist, Li Ka Shing Knowledge Institute \\
\hline & Associate Professor, University of Toronto \\
\hline \multirow[t]{2}{*}{ Andrea Chiaramida, BA } & Course coordinator \\
\hline & $\begin{array}{l}\text { Administrative Assistant, The Hospital } \\
\text { for Sick Children }\end{array}$ \\
\hline \multirow[t]{3}{*}{ Natasha Saunders, MD, MSc } & Course faculty \\
\hline & $\begin{array}{l}\text { Associate Scientist \& Staff Physician, } \\
\text { The Hospital for Sick Children }\end{array}$ \\
\hline & Assistant Professor, University of Toronto \\
\hline \multirow[t]{2}{*}{ Matet Nebres, BSc } & Course faculty \\
\hline & $\begin{array}{l}\text { Senior Manager, Media Relations, The } \\
\text { Hospital for Sick Children }\end{array}$ \\
\hline
\end{tabular}

The course content included best-practices to prepare, submit, and peer-review scientific manuscripts, as well as strategies for engaging patients, caregivers, and families in all stages of research development and publication.

Publication School attendees learned about diverse publication science topics through a variety of media (for agenda please see Table 2). Interactive lectures provided guidance about a range of topics related to publication best practices across the research continuum, such as the use of reporting guidelines in academic writing, publication ethics, choosing an appropriate academic journal for submission, how to identify and avoid predatory journals, scholarly metrics, and how to give and respond to peer-review. Attendees were also provided with opportunities to engage in active learning and group activities to facilitate their learning (Table 3). For instance, Dr. Cobey complemented her 'Tools for Transparency' lecture by having attendees visit the Open Science Framework (OSF, [22]) and Open Researcher and Contributor ID (ORCID, [23]) websites to familiarize attendees with these resources and to create user accounts (see Tables 2 and 3). These resources are essential tools that researchers can use to enhance the transparency of their research processes and to claim their unique author identity, respectively. For many attendees, these activities facilitated attendees' first steps in these areas.

The Publication School attendees were also provided with a number of networking opportunities. Short networking opportunities occurred between lectures and interactive sessions (e.g., during nutrition breaks and lunch) as attendees mingled with each other and Publication School Faculty throughout the day. The wrap-up event for Day 1 was a patient engagement roundtable and networking event. During this event, attendees applied their learning to three faculty-inspired scenarios: Why engage patients and barriers to engagement; When to engage and how to report in manuscripts/reports; and How to identify patients and engage patients. Each scenario was presented by two faculty members who facilitated discussions with groups of attendees at separate tables in a communal area of the venue (see Tables 2 and 3 for details). These discussions were timed so as to allow attendee groups an equal amount of time at each table. At the end of each interval, attendees ranked their top five messages and individual attendees volunteered to collate these ranked responses and report to the entire class during Session 16. Following this engagement roundtable and networking event, attendees and faculty went to a local restaurant for dinner, where they continued to network in an informal and sociable manner.

Attendees and faculty used the hashtag \#EQPubSchool to communicate about the course [24]. A few examples include: "\#EQPubSchool The Plenary on how to engage patients in the publishing process is coming up shortly. @EQUATORNetwork @dmoher @OSSUtweets"; "Spent the past two days attending \#EQPubSchool in Toronto. 


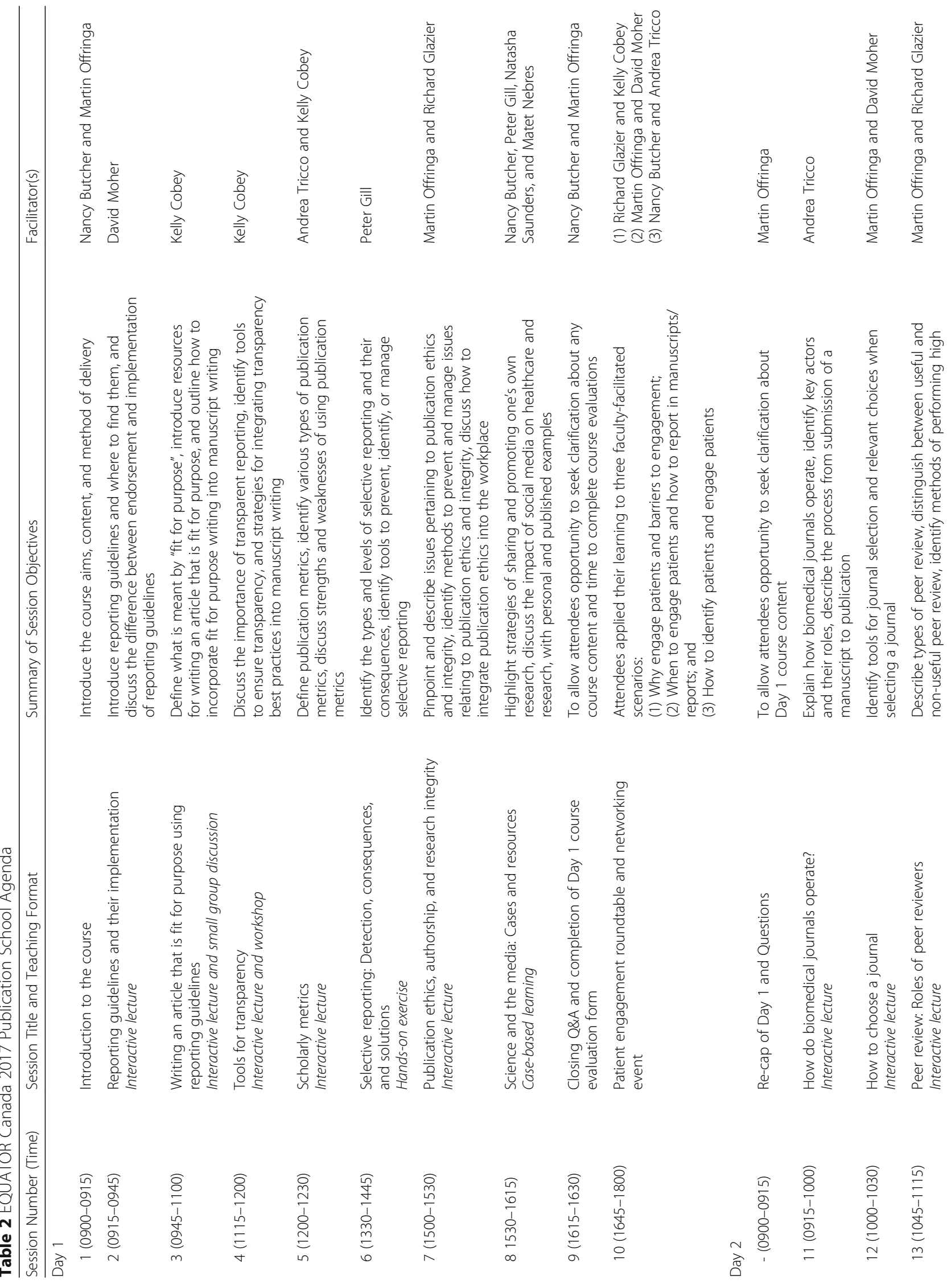




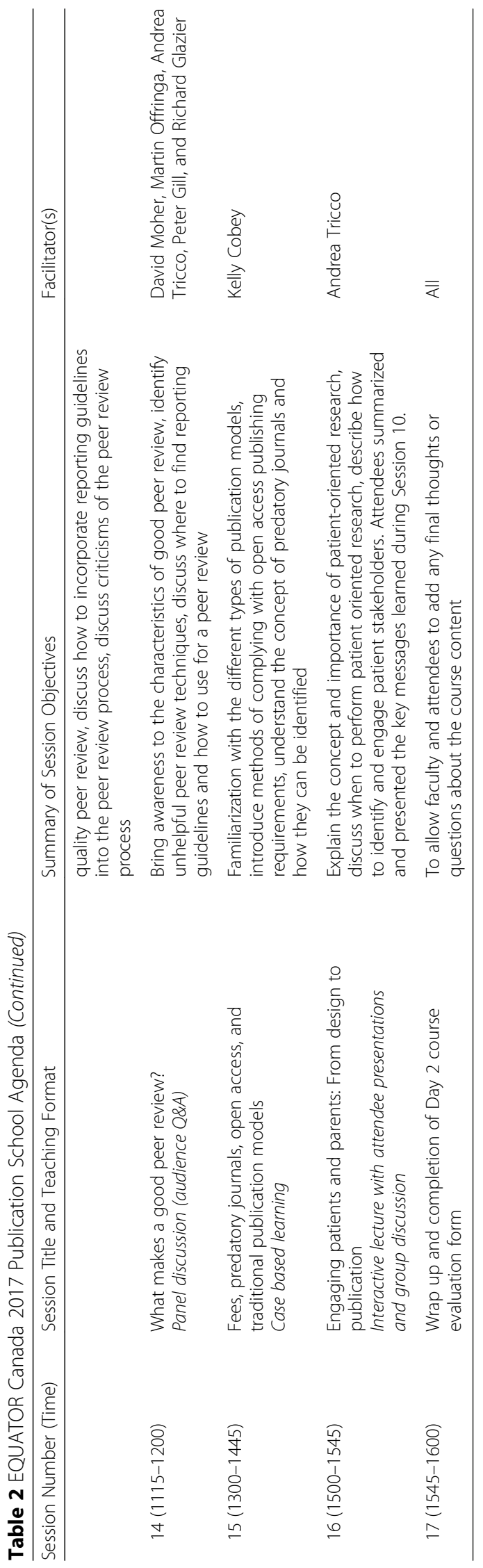


Table 3 Summary of interactive learning activities at the EQUATOR Canada 2017 Publication School

\begin{tabular}{|c|c|c|}
\hline Session & Title & Activity description \\
\hline 3 & $\begin{array}{l}\text { Writing an article that is fit for purpose using } \\
\text { a reporting guideline }\end{array}$ & $\begin{array}{l}\text { Peer review and assessment of fit for purpose writing of a published cohort study } \\
\text { through application of the STROBE reporting guideline }\end{array}$ \\
\hline 4 & Tools for Transparency & $\begin{array}{l}\text { Familiarization with Open Science Framework and ORCID to promote transparency } \\
\text { in research methodology }\end{array}$ \\
\hline 6 & $\begin{array}{l}\text { Selective reporting: Detection, consequences } \\
\text { and solutions }\end{array}$ & $\begin{array}{l}\text { Detection of selective reporting by comparing reported outcomes in a published } \\
\text { study protocol versus the published clinical trial report }\end{array}$ \\
\hline 10 & $\begin{array}{l}\text { Patient engagement roundtable and } \\
\text { networking event }\end{array}$ & $\begin{array}{l}\text { Attendees rotated between three tables led by two faculty each and brain-stormed } \\
\text { ideas and thoughts on (1) Why engage patients and barriers to engagement; ( } 2 \text { ) } \\
\text { When to engage patients and how to report in manuscripts/reports; and } \\
\text { (3) How to identify patients and engage patients. Attendees voted at each table on } \\
\text { the top five take-home messages and nominated a table "reporter" to present their } \\
\text { results to the course attendees during Session } 16 .\end{array}$ \\
\hline 15 & $\begin{array}{l}\text { Fees, predatory journals, open access, } \\
\text { and traditional publication models }\end{array}$ & $\begin{array}{l}\text { In groups, attendees applied their understanding of predatory journals in an examination } \\
\text { of three faculty-selected journal articles }\end{array}$ \\
\hline 16 & $\begin{array}{l}\text { Engaging patients and parents: From } \\
\text { design to publication }\end{array}$ & $\begin{array}{l}\text { Group discussion on engaging patients and parents, with student presentation of } \\
\text { take-home lessons learned from Session } 10\end{array}$ \\
\hline
\end{tabular}

Abbreviations: STROBE = Strengthening the Reporting of Observational Studies in Epidemiology, $O R C I D=$ Open Researcher and Contributor ID

Excited to apply the tools and tips to all things research. First step \#reportingguidelines @EQUATORNetwork". When the EQUATOR Canada Publication School came to a close, attendees were provided with an opportunity to stay in contact with each other and Publication School Faculty by joining a private LinkedIn group. This provided everyone with a networking opportunity to maintain long-term connections with current course participants, and to create a larger network with attendees of future EQUATOR Canada Publication School participants.

\section{EQUATOR Canada publication school application process and course attendees}

Information about the launch of the EQUATOR Canada Publication School was disseminated through various channels. E-mails were sent to universities across Canada and their respective medical schools and departments. Publication School information and the accompanying application form were posted on Cvent (www.cvent.com), an online event registration and management system. Social media platforms including Twitter and LinkedIn were also used to publicize the Publication School and application process.

Of the 65 individuals who applied to the inaugural Publication School, 34 were competitively selected using a comprehensive application process. This process required attendees to indicate: their primary role (e.g., clinician, graduate student, etc.); their research interests and current studies; whether they engage patients and families in their research; their use of social media for research dissemination; their purpose for attending the Publication School; their level of familiarity with publication science (e.g., reporting guideline usage, publication metrics); and topics or skills they would like to learn about or acquire from attending the Publication School. Applications were evaluated on a continuing basis and were reviewed by two to three planning committee members (e.g., the course co-directors and course co-ordinator). A consensus decision on acceptance was reached for all applicants.

The majority $(24 / 34,70.6 \%)$ registered as trainees (defined as graduate students, postdoctoral or clinical fellows, and medical students). The other registrants included physicians $(n=5)$, research associates $(n=2)$, and a scientist, a lecturer, and a research administrator. Two registrants did not attend the course. Of the 32 course attendees, 24 were female (75\%). Attendees were students or affiliated with medical and academic institutions that included The Hospital for Sick Children $(n=9)$, University of Toronto $(n=5)$, The Ottawa Hospital $(n=3)$, McMaster University $(n=3)$, Bruyére Research Institute $(n=2)$, Cancer Care Ontario $(n=2)$, Children's Hospital of Eastern Ontario $(n=2)$, Queen's University $(n=2)$, the Centre for Addiction and Mental Health $(n=1)$, McGill University $(n=1)$, Université Laval $(n=1)$, and World Child Cancer $(n=1)$.

Five trainees ( $n=3$ female) were awarded competitive scholarships to help offset the costs of attending the Publication School. The recipients were from McMaster University $(n=2)$, Queen's University $(n=1)$, Université Laval $(n=1)$ and The Ottawa Hospital $(n=1)$.

\section{The EQUATOR Canada publication school attendee evaluations and perspectives}

At the end of the Publication School, attendees provided verbal feedback during the course wrap-up (see Table 2). Nearly all $(28 / 32,87.5 \%)$ completed anonymous written course evaluations that were collected by Publication School Faculty. Of those that completed the course evaluation, most $(17 / 28,60.7 \%)$ indicated less than 5 years of publication experience; four (14.3\%) reported none. There were seven attendees with five to 10 years of publication 
experience. The completion rate of each item on the written evaluations ranged from 66 to $88 \%$ and overall the evaluations indicated that attendees perceived the Publication School content as well-organized, and highly relevant, and valuable to their diverse fields of research and clinical practice. All sessions and faculty were rated on average as between "very good" and "outstanding" on a five-point Likert scale. Of the attendees who provided general comments, many $(11 / 19,57.8 \%)$ indicated an appreciation for the expert mentorship of the Publication School Faculty and described them as e.g., "engaging", "enthusiastic", "knowledgeable", and "responsive".

Notably, verbal feedback included the suggestion by several participants that this type of course should be offered and integrated into formal training and course curricula. One participant commented in the written evaluation that "Would have liked to have done this course during residency training....we really don't get much/any formal training in this area. ... Given that the field is evolving/not static, course will be relevant for a long time to come."

Overall, Publication School attendees gained knowledge and learned a diversity of skills relevant to academic publishing (e.g., strategies and resources to maintain integrity of the scientific record; issues relevant to publication ethics, integrity and bias; selecting appropriate publication models; and how to implement the journalology process from manuscript submission to publication). The learning topics that resonated most among these attendee authors are summarized in the following sections and are complemented by the data provided within course evaluations. We believe these perspectives and lessons most poignantly describe our learning from the EQUATOR Canada Publication School and will provide readers with a summary of the valuable insights gleaned about academic publishing.

\section{Using reporting guidelines in all phases of the research process}

The results of the written course evaluations $(n=28)$ revealed that attendees agreed or strongly agreed that the course enhanced their knowledge and that content was relevant to their research practices. The majority $(26 / 28,92.8 \%)$ of attendees indicated that they would make changes to their research publication practices. Attendees were asked to list changes that they would make in their research practices (e.g., manuscript design and publication) as a result of participating in the course, and notably, the majority $(19 / 28,67.9 \%)$ self-identified the use reporting guidelines as an area of practice change. This is an important change for researchers to adopt, especially those beginning in their career, as reporting guidelines provide a standardized structure for the publication of research methods and results [12] that are increasingly being endorsed and required by academic journals during the manuscript submission and peer-review process in order to improve the quality of research reporting $[12,15]$. The attendees acknowledged the availability and diversity of reporting guidelines offered through the EQUATOR Network [13] and the relevance of these guidelines to all phases of the research process. For example, using reporting guidelines to draft a study protocol ensures that all relevant content is included in the protocol, resulting in a more comprehensive study design. Furthermore, publishing such as a protocol prior to carrying out the study facilitates readers' identification of selective reporting and critical appraisal of study results. Participants noted, for example, that they would "use reporting guidelines when designing my studies", "always use "Reporting Guidelines' while writing and reviewing papers", and "use reporting guidelines for every paper (not just RCT)".

Attendee authors value the use of reporting guidelines to facilitate peer-review of manuscripts submitted for publication. This was an important topic for this group of attendees, the majority of which were trainees and early in their career of academic publishing. We, the next generation of peer reviewers, appreciated the interactive learning session during Session 3 (see Tables 2 and 3) that provided us with some experiential insight into the world of peer-review. In Session 3's activity, we used an applicable reporting guideline (STROBE [Strengthening the Reporting of Observational Studies in Epidemiology; [25]) to critically appraise a published article for its alignment with the STROBE elements. The activity clearly illustrated for us the variation of reporting clarity that can exist in a single publication and therefore the importance of using reporting guidelines to guide the peer-review process. In the written course feedback, some $(3 / 19,15.7 \%)$ attendees suggested that further information about how to improve peer-review skills be considered for inclusion into future Publication Schools, however, one attendee commented that "the time spent on peer-review was longer than necessary". For attendees wishing to learn more about the peer-review process and/or improve their peer-review skills, they were encouraged to access reputable online resources such as those made available by the Publons community [26].

\section{Using metrics beyond the impact factor}

Another common area of self-identified research practice change in the course evaluations was in the area of journal selection. Nearly half $(11 / 26,42.3 \%)$ of the respondents who identified what they would do different in their research practice wrote that they would make changes to their process of selecting a journal to submit a manuscript. A new revelation for attendees was consideration of scholarly metrics beyond the popular journal impact factor (JIF). Attendees were introduced to the limitations of JIFs, for example, that $65-75 \%$ of articles in any given journal 
have a citation count below the journal's impact factor [27]. Indeed, a declaration advocating for "robust and time-efficient ways of evaluating research" whereby researchers do not rely on JIFs, was initiated in 2012 [28] and was introduced to attendees during this session. This declaration, referred to as the Declaration On Research Assessment (DORA, [28]) is endorsed by international groups and academics who recognize the deficiencies of the journal impact factor and support the need for improved evaluation of research output. Learning about scholarly metrics apart from the JIF was a source of important learning for attendees, who cited an appreciation for and intended use of other metrics for journals (SNIP [Source Normalized Impact per Paper]), articles (e.g., Altmetric) and researchers (e.g., H-Index).

\section{Open-access and alternative avenues for publication}

Another important source of learning for attendees was about open-access publication models. Attendees were introduced to the availability and procedures for open-access publishing and learned about information and resources useful to navigate this process. We appreciated learning about resources such as the Directory of Open Access Journals (DOAJ, [29]), which is a useful resource against predatory journals. DOAJ is a freely accessible online directory of reputable, open-access, peer-reviewed journals. Learning about these resources and other relevant information (e.g., article processing fees [APCs], archiving, repositories) were invaluable to facilitate the processes that we will follow when preparing and submitting our manuscripts for publication.

Attendees also appreciated learning about research dissemination methods beyond traditional academic publishing, as reflected in the course evaluation forms. The majority of respondents $(20 / 28,71.4 \%)$ reported that they are more likely to use social media to disseminate results of their research after completing the Publication School. Our discussion about useful media options to disseminate research included: Twitter and other social media platforms; blogging; podcasts; writing for institutional or association newsletters or magazines; and opportunities for dissemination through participation (e.g., public disease 'awareness weeks', at local library activities, Café Scientifiques). We found it particularly useful to hear from a local researcher and member of the Publication School Faculty, Dr. Natasha Saunders, who had her research findings recently highlighted on television and other media. Hearing Dr. Saunders' perspectives about contacting and preparing for this media coverage broadened our awareness for using dissemination strategies to reach beyond academic audiences. For those of us who are new adopters of social media dissemination strategies, we learned about useful resources to facilitate our understanding about how media can be used (e.g., TED Talks or lynda.com about how to use Twitter).

\section{Discussion}

In this paper, we have described the inaugural EQUATOR Canada Publication School, and have included the perspectives of Publication School attendees. During this EQUATOR Canada Publication School, attendees were introduced to the principles of publication science and exposed to a wide range of topics, practices, and resources related to the publication process. The Publication School provided a platform that fostered constructive dialogue about contemporary challenges facing the broader scholar community (e.g., oligopoly of commercial publishers in the biosciences, democratization of knowledge, open-access, and green archiving); addressed early-career researchers' concerns and learning needs across disciplines; and equipped attendees with resources to facilitate success with the publication process. In this way, we - attendees of the inaugural EQUATOR Canada Publication School gained an understanding about the myriad of factors that can influence and impact integrity of the scientific record, and how to access strategies and resources to manage these factors.

Evaluations submitted by attendees provided evidence that the content and structure of the Publication School was well-received and highly applicable to their respective fields. The majority of attendees reported that the course influenced them to make changes to their current research practice, whether that be using reporting guidelines, using the media to disseminate research, or generally being more transparent with their research processes. Most attendees provided perspectives about the impact of the Publication School that resonate with existing recommendations from the EQUATOR Network and experts in the field of publication science. These perspectives included the adoption and use of reporting guidelines in all phases of the research process, using metrics beyond the journal impact factor, and using open-access and alternative avenues for dissemination. Feedback received from Publication School attendees demonstrate the usefulness of this approach and relevance for researchers across their career trajectories (e.g., from trainees to clinician-scientists or academics).

\section{Limitations and recommendations}

Although all available $(n=28)$ attendee feedback was reviewed while preparing this manuscript, the perspectives reflected also reflect those of the attendee authors (JG, AC, SG, AJ, AM). It is recognized that the perspectives presented herein may not reflect all Publication School attendees who did not co-author this manuscript.

The evaluative data from attendees presented in this paper were only collected at end of the Publication School. 
In this way, pre- and post- comparisons of Publication School learning were not possible, and any changes in research publication, review, or dissemination practices occurring since the Publication School were not evaluated and are outside the scope of this paper. A limitation of the course identified in attendees' evaluations was that the Publication School curriculum largely focused on the biomedical sciences and was most applicable to quantitative research paradigms. Colleagues belonging to Nursing, Rehabilitation Science, Sociology and other similar disciplines suggested that the curriculum could be broadened to include topics such as research integrity and bias in qualitative or mixed-method research.

Notably, some early-career attendees recommended that the Publication School curriculum could be offered as two separate programs in the future. For example, a novice program could be offered to attendees with little to no publication experience, whereas an advanced level could be offered to attendees with publication experience and needing exposure to advanced topics. This phased approach may provide a more suitable curriculum to meet the needs and experiences of prospective attendees. Other attendees felt that the Publication School duration could have been longer (i.e., more than 2 days to cover the course curriculum).

A notable recommendation proposed by one attendee was that organizers of the Publication School reach out to program directors at universities to facilitate the incorporation of Publication School content within curricula to improve the journalology skills among novice researchers.

\section{Conclusion}

Publication of manuscripts in a scholarly journal is a commonly used method of disseminating research findings that is not without limitations and bias. The EQUATOR Canada Publication School represents one approach to help improve the transparency and quality of research reporting through education and outreach to researchers. Through this course, the EQUATOR Canada Publication School faculty addressed an array of key publication science topics (e.g., use of reporting guidelines, education around predatory journals, and patient engagement in research) through the use of didactic lectures, interactive workshops, and networking activities. This approach could be used, modified, and adapted to reflect the needs of different disciplines and undergraduate and graduate levels. The attendees' responses to the Publication School indicate that this content fulfills an important unmet need in publication science training among academics. The adoption of formal publication science training promises to help improve research reporting and dissemination skills among researchers in all disciplines of academia.

\section{Abbreviations}

APC: Article processing fees; CPD: Continuing professional development: DOAJ: Directory of Open Access Journals; DORA: Declaration On Research Assessment; EQUATOR: Enhancing the QUAlity and Transparency Of health Research; ORCID: Open researcher and contributor ID; OSF: Open science framework; OSSU: Ontario strategy for patient-oriented research support unit; SNIP: Source normalized impact per paper; STROBE: Strengthening the reporting of observational studies in epidemiology

\section{Acknowledgements}

This paper is dedicated to the memory of Dr. Doug Altman, founder of the EQUATOR Network. The authors would like to acknowledge Andrea

Chiaramida for course and manuscript administrative support and Leena Saeed who collated course evaluations and attendee feedback. The authors thank the course faculty and planning committee members who helped make this course possible. Drs. Martin Offringa and David Moher have reviewed this manuscript and have confirmed that an accurate meeting summary has been presented.

\section{Funding}

Funding for the EQUATOR Canada Publication School was provided by the Ontario SPOR Support Unit (OSSU). Meeting space was provided, in-kind, by the Peter Gilgan Centre for Research and Learning at the Hospital for Sick Children in Toronto, Ontario, Canada. Publication charges for this article have been funded by Hospital for Sick Children through funding provided by OSSU to support the EQUATOR Canada Publication School. OSSU had no role in the planning, drafting, or decision to publish this manuscript. ACT is funded by a Tier 2 Canada Research Chair in Knowledge Synthesis.

\section{Availability of data and materials}

The anonymized aggregate data from the written course evaluations is available on the Open Science Framework (osf.io/rchne).

\section{Authors' contributions}

$J G$ conceived the idea for this manuscript and led the initial drafting of the paper. AC, SG, AJ, AM were equal contributors to manuscript content. ACT and KDC provided feedback on the planning of this manuscript, and critically reviewed and provided feedback on the drafted manuscript. NJB supervised all phases of manuscript conceptualization, drafting, and submission, and critically reviewed and provided feedback on the manuscript. All authors have read and approved the final version of this manuscript.

\section{Author information}

Jacqueline Galica ",*; jacqueline.galica@queensu.ca; ORCID: 0000-0002-3072-2472. Alyssandra Chee-a-tow²; alyssandra.chee.a.tow@mail.utoronto.ca; ORCID: 0000-0003-0220-2717.

Shikha Gupta3; shikha.gupta@queensu.ca; ORCID: 0000-0002-5704-1618. Atul Jaiswal $^{3}$; atul.jaiswal@queensu.ca; ORCID: 0000-0001-5700-2283. Andrea Monsour²; andrea.monsour@sickkids.ca; ORCID: 0000-0003-3870-3804. Andrea C. Tricco 4,5; TriccoA@smh.ca; ORCID: 0000-0002-4114-8971. Kelly D. Cobey ${ }^{6,7,8}$; kcobey@ohri.ca; ORCID: 0000-0003-2797-1686. Nancy J. Butcher²; nancy.butcher@sickkids.ca; ORCID: 0000-0002-5152-0108.

Ethics approval and consent to participate

Ethics review was not required for this manuscript, as per the Research Ethics Board at the Hospital for Sick Children.

Consent for publication

Not applicable.

\section{Competing interests}

Drs. Butcher, Tricco, and Cobey were involved in the planning and delivery of the EQUATOR Canada Publication School. All other authors have no competing interests to declare.

\section{Publisher's Note}

Springer Nature remains neutral with regard to jurisdictional claims in published maps and institutional affiliations. 


\section{Author details}

'School of Nursing, Faculty of Health Sciences, Queen's University, Kingston, Canada. ${ }^{2}$ Child Health Evaluative Sciences, The Hospital for Sick Children Research Institute, Toronto, Canada. ${ }^{3}$ School of Rehabilitation Therapy, Queen's University, Kingston, Canada. ${ }^{4}$ Epidemiology Division, Dalla Lana School of Public Health, University of Toronto, Toronto, Canada. ${ }^{5} \mathrm{Li}$ Ka Shing Knowledge Institute of St. Michael's Hospital, Toronto, Canada. ${ }^{6}$ Centre for Journalology, Ottawa Hospital Research Institute, Ottawa, Canada. ${ }^{7}$ School of Epidemiology and Public Health, University of Ottawa, Ottawa, Canada. ${ }^{8}$ Department of Psychology, University of Stirling, Stirling, Scotland.

\section{Published: 23 August 2018}

\section{References}

1. Wilson PM, Petticrew M, Calnan MW, Nazareth I. Disseminating research findings: what should researchers do? A systematic scoping review of conceptual frameworks. Implement Sci. 2010; https://doi.org/10.1186/17485908-5-91.

2. Liberati A. An unfinished trip through uncertainties. BMJ. 2004;328:531.

3. Chan AW, Song F, Vickers A, Jefferson T, Dickersin K, Gøtzsche PC, et al. Increasing value and reducing waste: Addressing inaccessible research. Lancet. 2014; https://doi.org/10.1016/S0140-6736(13)62296-5.

4. Liberati A. So many questions, so few answers. Interview by Les Olson. Bull World Health Organ. 2010; https://doi.org/10.2471/BLT.10.030810.

5. Scherer RW, Langenberg P, von Elm E. Full publication of results initially presented in abstracts. Cochrane Database Syst Rev. 2007; https://doi.org/10, 1002/14651858.MR000005.pub3.

6. Glasziou P, Altman DG, Bossuyt P, Boutron I, Clarke M, Julious S, et al. Reducing waste from incomplete or unusable reports of biomedical research. Lancet. 2014; https://doi.org/10.1016/S0140-6736(13)62228-X.

7. Chalmers I, Glasziou P. Avoidable waste in the production and reporting of research evidence. Lancet. 2009;374:86-9.

8. Galipeau J, Moher D, Campbell C, Hendry P, Cameron DW, Palepu A, et al. A systematic review highlights a knowledge gap regarding the effectiveness of health-related training programs in journalology. J Clin Epidemiol. 2015; https://doi.org/10.1016/j.jclinepi.2014.09.024.

9. Keen A. Writing for publication: pressures, barriers and support strategies. Nurse Educ Today. 2007; https://doi.org/10.1016/j.nedt.2006.05.019.

10. Aitchison C, Catterall J, Ross P, Burgin S. "Tough love and tears": Learning doctoral writing in the sciences. High Educ Res Dev. 2012; https://doi.org/ 10.1080/07294360.2011.559195.

11. Government of Canada/Gouvernement du Canada. Tri-Agency Open Access Policy on Publications. (n.d.). http://www.science.gc.ca/eic/site/063.nsf/eng/ h_F6765465.html?OpenDocument. Accessed 6 Apr 2018.

12. Simera I, Moher D, Hoey J, Schulz KF, Altman DG. A catalogue of reporting guidelines for health research. Eur I Clin Investig. 2010; https://doi.org/10. 1111/j.1365-2362.2009.02234.X.

13. EQUATOR Network. EQUATOR Network. http://www.equator-network.org/ (n.d.). Accessed 6 Apr 2018.

14. Turner L, Shamseer L, Altman DG, Schulz KF, Moher D. Does use of the CONSORT statement impact the completeness of reporting of randomised controlled trials published in medical journals? A Cochrane review. Syst Rev. 2012; https://doi.org/10.1186/2046-4053-1-60.

15. Larson EL, Cortazal M. Publication guidelines need widespread adoption J Clin Epidemiol. 2012; https://doi.org/10.1016/j.jclinepi.2011.07.008.

16. EQUATOR Network. Australasian EQUATOR Centre. https://www.equatornetwork.org/2016/02/22/new-australasian-equator-centre-opening-in-march/ (n.d.). Accessed 12 Jun 2018

17. EQUATOR Network. Canadian EQUATOR Centre. http://www.equator-network. org/about-us/canadian-equator-centre/ (n.d.). Accessed 12 Jun 2018.

18. EQUATOR Network. French EQUATOR Centre. http://www.equator-network. org/about-us/french-equator-centre/ (n.d.). Accessed 12 Jun 2018.

19. EQUATOR Network. UK EQUATOR Centre. http://www.equator-network.org/ about-us/uk-equator-centre/ (n.d.). Accessed 12 Jun 2018.

20. EQUATOR Network. Upcoming events. https://www.equator-network.org/ category/events/upcoming-events/ (n.d.). Accessed 12 Jun 2018.

21. Ontario SPOR Support Unit. Ontario SPOR Support Unit. www.ossu.ca (2018). Accessed 5 Apr 2018.

22. Foster ED, Deardorff A. Open Science Framework (OSF). J Med Libr Assoc. 2017; https://doi.org/10.5195/JMLA.2017.88.
23. Open Researcher and Contributor iD. Open Researcher Contributor iD. https://orcid.org/. (n.d.). Accessed 5 Apr 2018.

24. Twitter Feed. https:/twitter.com/search?q=\%23EQPubSchool\&src=typd. (n.d.).

25. von Elm E, Altman DG, Egger M, Pocock SJ, Gøtzsche PC, Vandenbroucke $J P$. The strengthening the reporting of observational studies in epidemiology (STROBE) statement: guidelines for reporting observational studies. J Clin Epidemiol. 2008; https://doi.org/10.1016/j.jclinepi.2007.11.008.

26. Publons. Publons. https://publons.com/home/ (n.d.). Accessed 12 Jun 2018.

27. Lariviere V, Kiermer V, MacCallum CJ, McNutt M, Patterson M, Pulverer B, et al. A simple proposal for the publication of journal citation distributions. BioRxiv. 2016; https://doi.org/10.1101/062109.

28. San Francisco Declaration on Research Assessment. San Francisco Declaration on Research Assessment. https://sfdora.org/ (n.d.). Accessed 6 Apr 2018.

29. Directory of Open Access Journals. https://doaj.org/ (n.d.). Accessed 23 Apr 2018.
Ready to submit your research? Choose BMC and benefit from:

- fast, convenient online submission

- thorough peer review by experienced researchers in your field

- rapid publication on acceptance

- support for research data, including large and complex data types

- gold Open Access which fosters wider collaboration and increased citations

- maximum visibility for your research: over $100 \mathrm{M}$ website views per year

At $\mathrm{BMC}$, research is always in progress.

Learn more biomedcentral.com/submissions 